\title{
Life Cycle Effects on the Vertical Structure of Precipitation in East China Measured by Himawari-8 and GPM DPR
}

\author{
AOQI ZHANG AND YunFeI Fu \\ School of Earth and Space Sciences, University of Science and Technology of China, Hefei, China
}

(Manuscript received 8 March 2018, in final form 10 May 2018)

\begin{abstract}
We identified precipitating systems from May to August 2016 using data from the Global Precipitation Measurement mission Dual-frequency Precipitation Radar instrument. Then, using this set of cases, Himawari-8 10.4- $\mu \mathrm{m}$ brightness temperature data from before and after each precipitation event were used to identify three life stages of clouds: a developing stage, a mature stage, and a dissipating stage. Using statistical analysis and two case studies, we show that the precipitating systems at different life stages of the clouds have different systematic properties, including the area of precipitation, the convective ratio, the rain-top height, and the brightness temperature. The developing systems had the largest convective ratio, whereas the dissipating systems had the largest area of precipitation. The life stage of the cloud also influenced the vertical structure of the precipitation. The microphysical processes within each stage were unique, leading to various properties of the droplets in precipitation. The developing systems had large, but sparse, droplets; the mature systems had large and dense droplets; and the dissipating systems had small and sparse droplets. Our results suggest that the different properties of precipitating systems in each life cycle stage of clouds are linked to the cloud water content and the upward motion of air.
\end{abstract}

\section{Introduction}

The vertical structure of precipitation reflects both the thermal and dynamic properties of precipitation systems and the microphysical processes of ice and water particles in clouds (Houze 1981; Hobbs 1989; Zipser and Lutz 1994; Fu and Liu 2001). Among the methods available for observing precipitation, rain gauges only record the near-surface rainfall at specific positions, whereas precipitation radar systems give the three-dimensional structure of precipitation, including the horizontal distribution and vertical profile (Barros et al. 2000; Inoue and Aonashi 2000; Fu et al. 2003; Fisher 2004; Chen et al. 2016). Precipitation radar systems include both groundand space-based systems, although ground-based radar observations are limited by their geographical location and are vulnerable to terrain shielding. Space-based radar systems are therefore the most effective method of revealing the regional and global structure of precipitation (Simpson et al. 1988; Hou et al. 2014).

Numerous studies on precipitation structures have been carried out based on observations from the Tropical

Corresponding author: Yunfei Fu, fyf@ustc.edu.cn
Rainfall Measuring Mission (TRMM) Precipitation Radar (PR) and the Global Precipitation Measurement (GPM) mission Dual-frequency Precipitation Radar (DPR) systems (Barros et al. 2000; Berg et al. 2002; Schumacher and Houze 2003; Fisher 2004; Fu et al. 2006; Inoue and Aonashi 2000; Liu et al. 2013; Liu and Zipser 2015). For instance, Berg et al. (2002) conducted a statistical analysis of precipitating features in the western and eastern Pacific Ocean and showed that precipitation in the eastern Pacific has higher tops, a larger proportion of stratiform precipitation, and a lower ice water content than precipitation in the western Pacific. Fu et al. (2006) studied isolated convection over the Tibetan Plateau and found a "tower mast" shape of precipitation structures. Liu and Zipser (2015) focused on the global distribution of the largest, deepest, and most intense precipitation systems and found that the zonal contribution of precipitation from extremely large precipitation systems was greater at mid- and high latitudes than in the tropics. Using GPM DPR products in June-September from 2014 to 2016, Zhang et al. (2018) investigated the impact of surface flow on precipitating systems in the southern Himalaya, suggesting various triggers for precipitating systems with different surface flows. 
The effect of the three main stages of the life cycle of clouds (the developing, mature, and dissipating stages; Byers and Braham 1949; Fiolleau and Roca 2013a; Witte et al. 2014) has long been a focus of cloud studies. Takahashi (1975) suggested that the electrical properties of warm clouds are affected by their life stage. Cho (1977) reported that the life stage of cirrus clouds influences the large-scale transportation of heat and moisture. Other researchers have focused on heat and moisture processes within clouds. Using data from the Global Atmosphere Research Program Atlantic Tropical Experiment, Chen (1988) showed that the moisture supplement exceeds the amount of precipitation during the developing stage, and the water content of the cloud increases, while the opposite occurs during the dissipating stage. Zhao and Austin (2005) numerically simulated the life cycle of small and large cumulus clouds and suggested that there are differences in heat and moisture potentials between them. Witte et al. (2014) indicated that the volume-averaged total water mixing ratio is a useful way of identifying the life stages of clouds. The scale and proportion of convective precipitation also have been reported to change during the development of mesoscale convective systems (Mathon and Laurent 2001). These studies have shown that the life cycle of clouds has a huge impact on cloud properties and therefore also on the properties of precipitation.

Unfortunately, as a result of the discontinuity of spatiotemporal observations by space-based radar systems (Hou et al. 2014), research on the relationships between the life cycle of clouds and the characteristics of precipitation are limited. Observations from stationary satellites and other spatiotemporal data therefore need be introduced to determine the life stage of clouds. Carbone and Nelson (1978) carried out radar observations and airborne droplet size distribution (DSD) measurements and found that droplet concentrations were low in the growth stage of clouds, but high in the dissipating stage. Kondo et al. (2006) studied the dependence of rainfall on the life cycle of clouds in the Maritime Continent and western Pacific area using TRMM PR and geostationary data, showing that strong rain rates were observed in the early stage of development of mesoscale convective systems, followed by a gradual decrease in the rain rate. Inoue et al. (2009) suggested the strong rain rates in the early stages may be linked with the limited occurrence of cirrus clouds over the eastern Pacific region. Fiolleau and Roca (2013b) provided further quantified evidence that rainfall is strong during the first third of the life cycle of clouds and then decreases smoothly as the system shrinks and dissipates over both land and oceanic regions. These studies have laid a good foundation for studying the effect of the life cycle of clouds on precipitation features. However, most of these studies have been carried out at the Earth's surface or at a specific height. Research on the relationship between the vertical structure of precipitation and the life cycle of clouds is limited, and the microphysical features of precipitation particles have yet to be determined.

We combined observations from the Himawari-8 geostationary satellite and the GPM DPR instrument to focus on the effect of the life cycle of clouds on the vertical structure of precipitating systems. High-spatiotemporalresolution data from the Himawari-8 geostationary satellite were used to determine the life stages of precipitating systems detected by the DPR instrument. Using both case studies and statistical studies, we analyzed the vertical features of clouds-including the radar reflectivity, rain-rate, and DSD profiles-and analyzed the microphysical processes in droplets in each life cycle stage of clouds. The results provide an observational basis for numerically simulating the development of precipitation systems and help to refine forecasts of precipitation.

\section{Data and methods}

\section{a. Instruments and datasets}

The precipitation data used in this study were from the GPM DPR. As a follow-up to the TRMM PR instrument, the GPM DPR system began operating in February 2014 with coverage from $65^{\circ} \mathrm{S}$ to $65^{\circ} \mathrm{N}$. The DPR system consists of a Ku-band radar (KuPR) and a Ka-band radar (KaPR), which operate at 13.6 and $35.5 \mathrm{GHz}$, respectively; see Kotsuki et al. (2014) for a description of the sampling methods. The KuPR scans in the same way as the TRMM PR, with a minimum detectable reflectivity of $14.5 \mathrm{~dB} Z$. The KaPR has two scan modes: a matched scan and a high-sensitivity scan, with minimum detectable reflectivities of 16.7 and $10.2 \mathrm{~dB} Z$, respectively (Hamada and Takayabu 2016). Because of the shorter wavelength of Ka-band, KaPR is more sensitive to small hydrogels but restricted in detecting intense precipitation as a result of the Mie scattering effect, while it is just the opposite for KuPR (L'Ecuyer and Stephens 2002; Kojima et al. 2012). As a result of the different responses, the GPM has developed dualfrequency algorithms to provide users with a dualfrequency precipitation product 2ADPR (Rose and Chandrasekar 2006; Iguchi et al. 2012). In the dualfrequency algorithm, first the DSD profiles are retrieved from radar reflectivity of KaPR and KuPR, and then the rain-rate profiles are provided based on the DSD profiles. The effectiveness of the 2ADPR product has been 
verified by a number of researchers (Hamada and Takayabu 2016; Kotsuki et al. 2014; Zhang et al. 2018). In this study, we used radar reflectivity, rain-rate profiles, rain type, DSD profiles, and other precipitation parameters from the $2 \mathrm{ADPR}$ product. In the $2 \mathrm{ADPR}$ product, precipitation pixels are classified into three rain types: convective, stratiform, and other. The shallow type is contained in the convective type. These profiles are provided at a vertical resolution of $125 \mathrm{~m}$ and a horizontal resolution of $5 \mathrm{~km}$.

Himawari-8 is a geostationary satellite developed by the Japan Meteorological Agency. Himawari- 8 has been operating at $140.7^{\circ} \mathrm{E}$ longitude since July 2015 and is equipped with the Advanced Himawari Imager, which has 16 observing bands from 0.47 to $13.3 \mu \mathrm{m}$. The Advanced Himawari Imager scans the full disk once in each 10-min period, and its pixels are sampled at spatial resolutions of $0.5,1$, and $2 \mathrm{~km}$ in different channels (Bessho et al. 2016). Measurements made by the Advanced Himawari Imager were preliminary assessed by Da (2015). This study used the $10.4-\mu \mathrm{m}$ brightness temperature, which is provided at a spatial resolution of $2 \mathrm{~km}$. The Himawari-8 data were matched to the 2ADPR data using a closest point algorithm.

\section{b. Identifying precipitating stages}

Considering the cloud stage is unique within one precipitating system, we first need to identify the DPR precipitating systems. Precipitation systems were defined here as contiguous DPR rainfall pixels (Nesbitt et al. 2000). This identification method has been used previously in many TRMM PR and GPM DPR studies (Liu and Zipser 2005; Houze et al. 2007; Liu and Zipser 2015; Zhang et al. 2018).

We next identified the life stage of the cloud in each precipitating system with $>100$ DPR pixels. The algorithm used previously to identify the life stage of MCSs used a brightness temperature threshold to delineate contiguous cloudy pixels and track them based on the overlap of the MCS between two consecutive images (Williams and Houze 1987; Arnaud et al. 1992; Mapes and Houze 1993; Machado et al. 1998). However, because the DPR precipitating system pixels are not always the same as the Himawari-8 mesoscale convective system pixels, the method may introduce uncertainties. We therefore manually compared the brightness temperature changes before and after precipitation events. Based on the stage division of thunderstorms in Byers and Braham (1949), the life cycle of a cloud consists of a developing stage, a mature stage, and a dissipating stage. In the developing stage, the brightness temperature of cloud gradually decreases, while the cloud area gradually increases. In the mature stage, the brightness temperature of precipitating cloud changes little before and after precipitation events. In the dissipating stage, the brightness temperature of cloud gradually increases. Figure 1 shows the identification process of a developing cloud, in which the labels $(-4,-3$, and $-2 \mathrm{~h})$ represent the time difference between the Himawari-8 images and the precipitating system. The brightness temperature gradually decreases over time as the area of the cloud increases, showing that the precipitation system is at the developing stage.

This method of identification was used in eastern China (Fig. 2) during the monsoon season (MayAugust) in 2016. Table 1 shows the number of precipitating systems, the average near-surface rain rates, and the convective ratio for each stage of the precipitating systems. As a precipitating system contains several precipitation pixels, the convective/stratiform ratio is defined as the percent of convective/stratiform pixels to the total pixels in the precipitating system. The numbers of precipitating systems in the developing, mature, and dissipating stages were 80,106 , and 94, respectively. Precipitating systems in the developing stage had the smallest area $\left(12188 \mathrm{~km}^{2}\right)$ and the largest proportion of convection $(26.2 \%)$, indicating strong convective activity in this stage. The convective ratio in mature precipitating systems $(21.5 \%)$ was slightly smaller than in the developing stage, although the average near-surface rain rate $\left(4.16 \mathrm{~mm} \mathrm{~h}^{-1}\right)$ was at its highest. This suggests that there is sufficient water and therefore a large amount of precipitation in maturestage clouds. The precipitating systems in the dissipating stage had the smallest convective ratio $(14.45 \%)$ and the largest area $\left(21057.9 \mathrm{~km}^{2}\right)$. Therefore, although the average convective rainfall intensity $\left(8.46 \mathrm{~mm} \mathrm{~h}^{-1}\right)$ and the average stratiform intensity $\left(1.95 \mathrm{~mm} \mathrm{~h}^{-1}\right)$ in the dissipating stage were slightly larger than in the developing stage ( 7.15 and $1.9 \mathrm{~mm} \mathrm{~h}^{-1}$, respectively), the average rainfall intensity in the dissipating stage $\left(2.85 \mathrm{~mm} \mathrm{~h}^{-1}\right)$ was smaller than in the developing stage $\left(3.23 \mathrm{~mm} \mathrm{~h}^{-1}\right)$.

Additionally, the regional distributions of precipitating systems in developing stage, mature stage, and dissipating stage were shown in Fig. 2. There was no significant difference in the regional distributions of precipitating systems at each stage. The reason for this phenomenon is likely that precipitation has been affected by the topography of eastern China, which needs to be further studied in detail in the future.

\section{Case studies}

Before studying the structural properties of precipitating systems statistically, we focused on two examples of the mature and dissipating stages of 


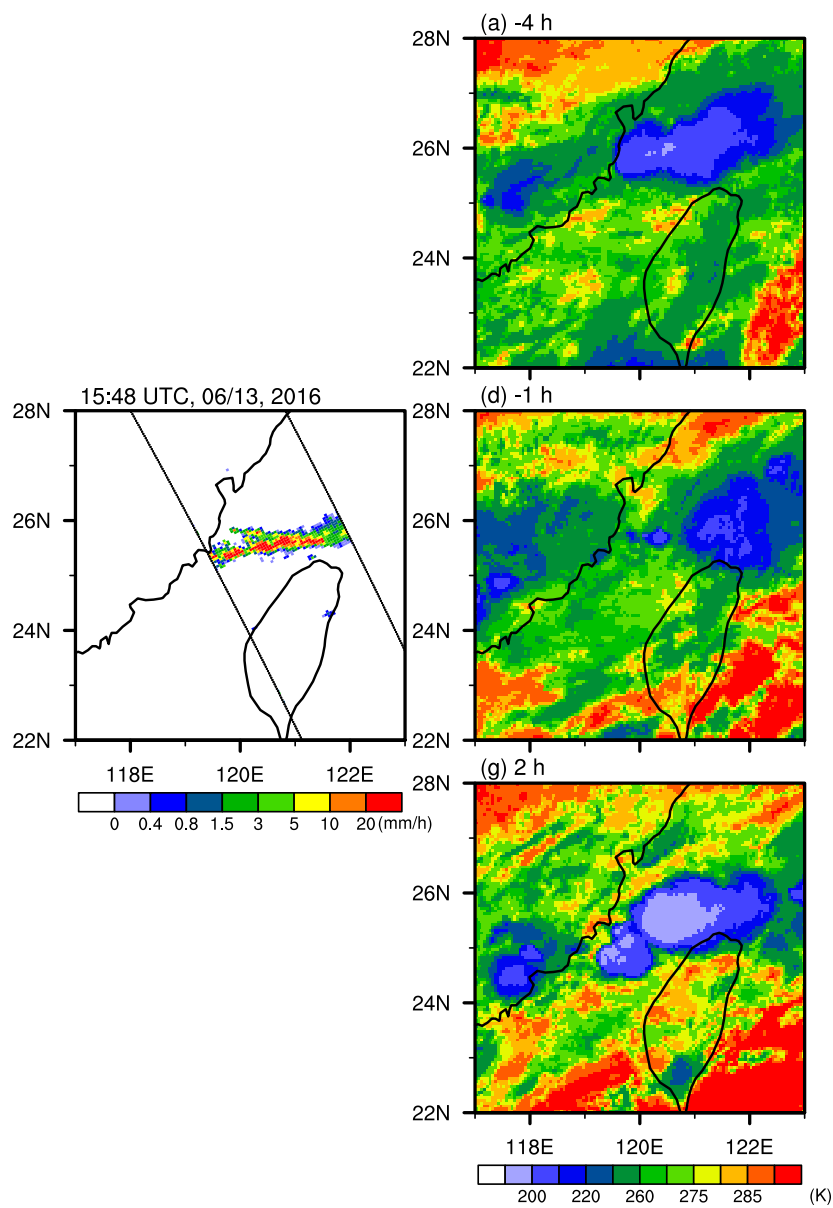

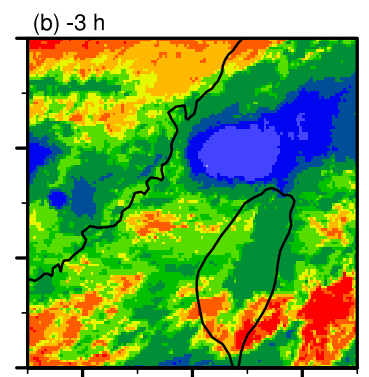
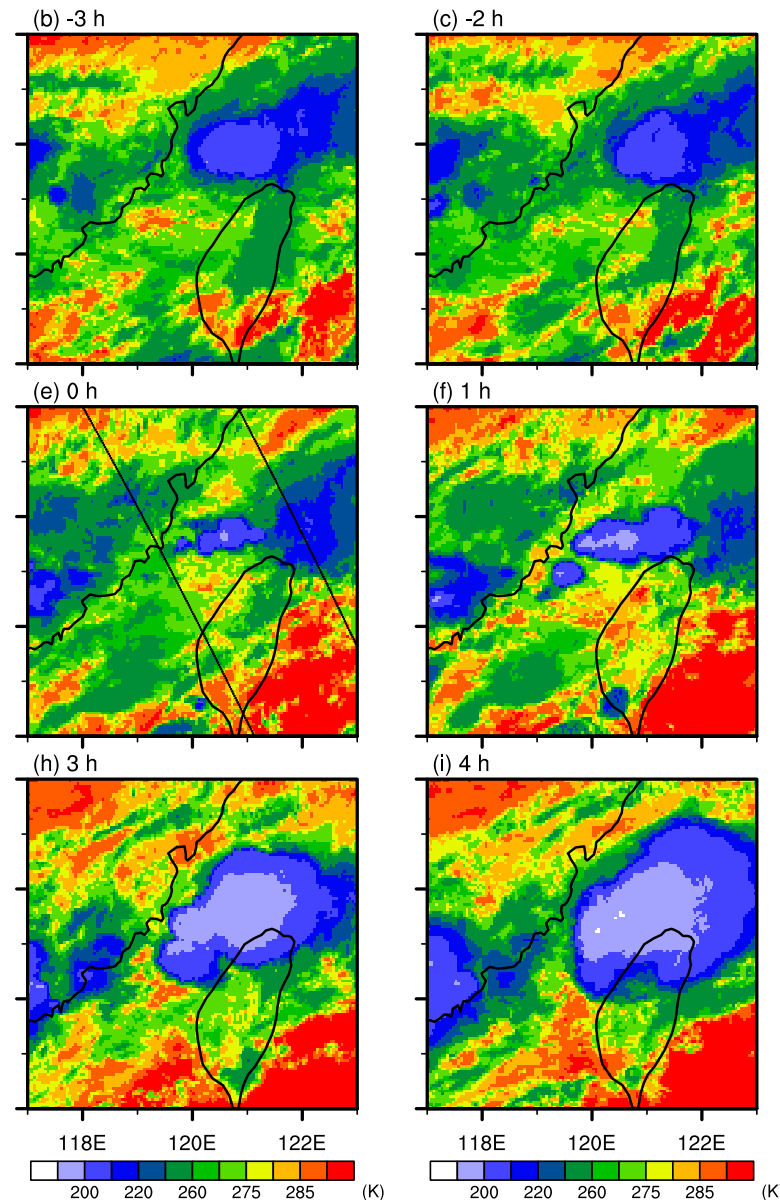

FIG. 1. Identification of a precipitating system in the developing stage of a cloud. (left) The distribution of the near-surface rain rate measured by the DPR instrument. (a)-(i) Distribution of the Himawari-8 10.4- $\mu \mathrm{m}$ brightness temperature at different times related to the precipitating events.

precipitation (the developing stage of precipitation was discussed in section $2 b$ ). These case studies provide detailed insights into the various stages of precipitation structures and lay a good foundation for the statistical study.
Figure 2 shows the Himawari-8 $10.4-\mu \mathrm{m}$ brightness temperature within $\pm 4 \mathrm{~h}$ of the precipitating events. The mature stage of a precipitating cloud was recorded near Hainan Island at 0220 UTC 2 August 2016 (Fig. 3e). At the time of precipitation, the lowest cloud brightness
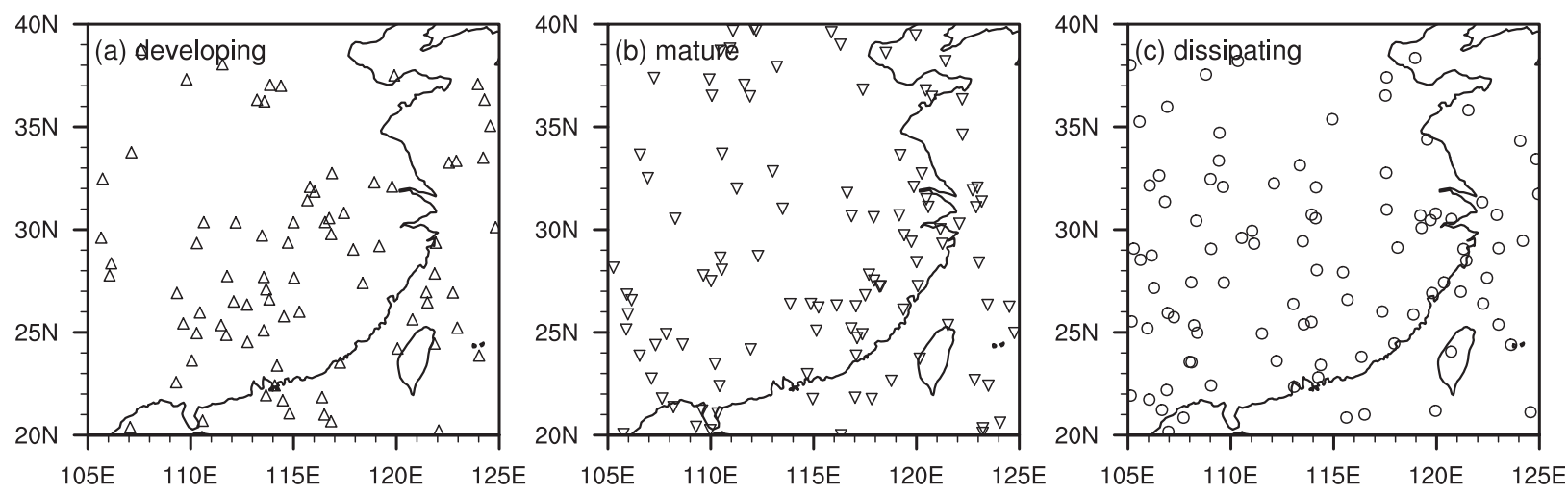

FIG. 2. Regional distribution of precipitating systems in (a) developing stage, (b) mature stage, and (c) dissipating stage. 
TABLE 1. Sample sizes, average near-surface rain rate, convective ratio, and stratiform ratio for precipitating systems in each life stage of clouds.

\begin{tabular}{lcrc}
\hline \hline & Developing stage & Mature stage & Dissipating stage \\
\hline Number of precipitating systems & 80 & 106 & 94 \\
Area of precipitating system $\left(\mathrm{km}^{2}\right)$ & 12188.4 & 17987.3 & 21057.9 \\
Near-surface rain rate $\left(\mathrm{mm} \mathrm{h}^{-1}\right)$ & 3.23 & 4.16 & 2.85 \\
Proportion of stratiform precipitation $(\%)$ & 70.95 & 72.23 & 2.24 \\
Near-surface rain rate of stratiform precipitation $\left(\mathrm{mm} \mathrm{h}^{-1}\right)$ & 1.9 & 21.46 & 1.95 \\
Proportion of convective precipitation $(\%)$ & 26.2 & 11.72 & 8.46 \\
Near-surface rain rate of convective precipitation $\left(\mathrm{mm} \mathrm{h}^{-1}\right)$ & 7.15 & 8.46 \\
\hline
\end{tabular}

temperature was $<190 \mathrm{~K}$ (Fig. 3e), and the area inside the cold cloud with a brightness temperature $<200 \mathrm{~K}$ was obviously larger than the area $2 \mathrm{~h}$ earlier (Fig. 3c) or later (Fig. 3g), indicating that the event was a typical precipitating system at the mature cloud stage. After the precipitating event, the cloud system gradually dissipated over time (Figs. 3g,i), and the area of the cloud reached its peak size during the dissipation stage (Fig. 3g), consistent with the results in Table 1.

The dissipating stage of the precipitating cloud was recorded in the northeast of Taiwan Island at 0510 UTC 14 June 2016 (Fig. 3f). From $6 \mathrm{~h}$ before to $2 \mathrm{~h}$ after the precipitation event (Fig. 3, right-hand panels), the cloud brightness temperature continuously split and dissipated; the area of the cloud was at a maximum $4 \mathrm{~h}$ before the precipitation event (Fig. 3d). At the time of the precipitation event, there were only a few areas of cold cloud with a brightness temperature $<200 \mathrm{~K}$ and irregular boundaries. These variations in the infrared temperature show that the precipitation event occurred during the dissipation stage of the cloud, corresponding to the diffusion and dissipation of the cloud.

Figure 4 shows the horizontal distribution, the cross section, and the contoured frequency by altitude diagram (CFAD) analysis for these two case studies. The precipitation system for the mature event consists of two parts: intense precipitation in the central region, surrounded by weak precipitation (Fig. 4a). The echo-top altitude in the central area reached $17 \mathrm{~km}$ (Fig. 4c), indicating penetrating convection (Liu and Zipser 2005; $\mathrm{Xian}$ and $\mathrm{Fu}$ 2015). The echo top in the surrounding area was seen at about $11 \mathrm{~km}$, and the echoes above the frozen layer $(\sim 6 \mathrm{~km})$ were significantly stronger than those below (Fig. 4c). These observations suggest that the surrounding weak precipitation was an example of anvil precipitation. The air below the anvil was still dry, so droplets of water evaporated when falling into the lower-level air, resulting in a decrease in reflectivity (Li and Schumacher 2011). The CFAD distribution (Fig. 4e) also showed two central intervals of 17-20 and $28-34 \mathrm{dBZ}$ below the frozen layer, corresponding to the surrounding anvil precipitation and central precipitation, respectively.

The horizontal distribution of the dissipating event was fairly uniform, without obvious zoning (Fig. 4b). The precipitation echoes were $9-13 \mathrm{~km}$ tall and appeared as typical stratiform rainfall with clear, uniform bright bands (Figs. 4d,f). The echoes below the bright band were significantly stronger than those above, whereas the near-surface echoes were $<50 \mathrm{~dB} Z$. These results show that the convective activity was weak during the dissipating stage and that the precipitation was dominated by stratiform precipitation, consistent with the statistical results given in Table 1.

\section{Statistical results}

\section{a. Brightness temperature and near-surface rain rate}

The 10.4- $\mu \mathrm{m}$ channel is an infrared split-window channel. It is less affected by the atmosphere and reflects information about the cloud top or Earth's surface. To obtain the differences between precipitating cloud tops at different stages, we analyzed the Himawari-8 $10.4-\mu \mathrm{m}$ channel brightness temperature $\left(\mathrm{TB}_{10.4}\right)$ for the precipitation events. The following statistics were all obtained from Himawari-8 images or DPR pixels in precipitating systems.

Figure 5 shows the probability distribution function (PDF) of the Himawari-8 $\mathrm{TB}_{10.4}$ data corresponding to the DPR precipitation pixels in each stage. In general, the mean brightness temperature of the mature stage of clouds was $10 \mathrm{~K}$ lower than the temperature of the other two stages, indicating that the precipitating cloud top of the mature stage was the highest. The mean brightness temperature of the dissipating stage was slightly lower than that of the developing stage, consistent with the conceptual model of Fiolleau and Roca (2013a). The PDFs of both the mature stage and the dissipating stage showed a single peak structure, both peaking at a brightness temperature of $220 \mathrm{~K}$. However, about $43 \%$ of the total precipitating pixels were accompanied by a 
Mature
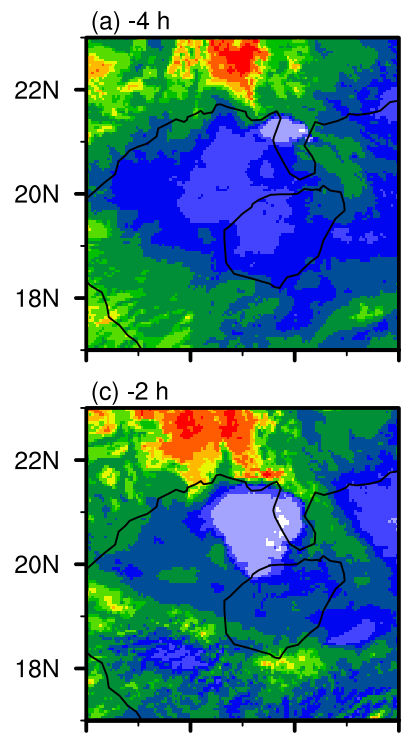

(e) 02:20 UTC, August 2, 2006
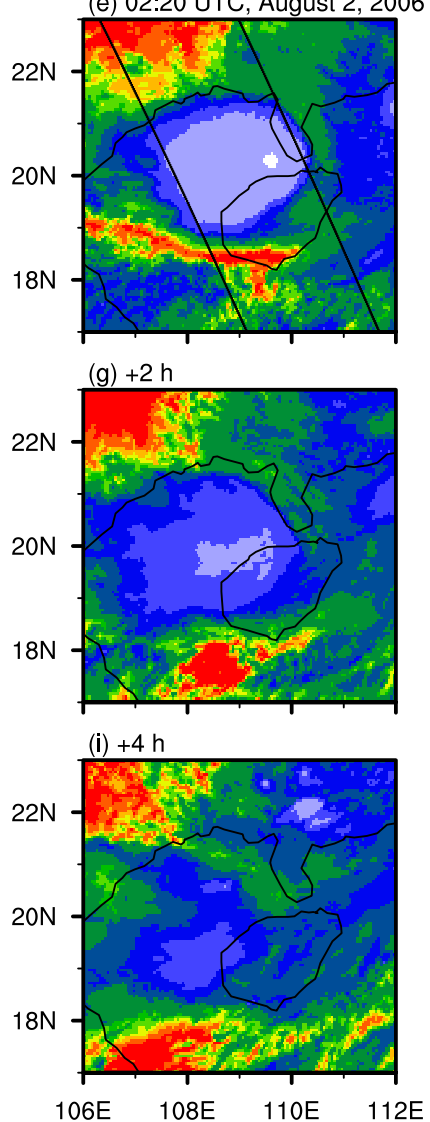

Dissipating
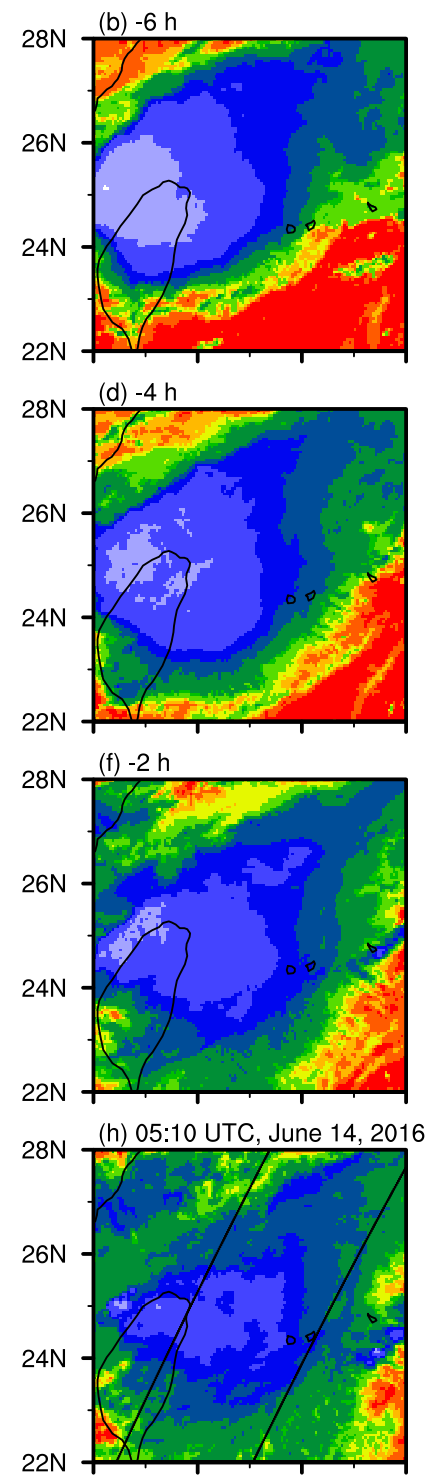

$28 \mathrm{~N}$ (j) $+2 \mathrm{~h}$

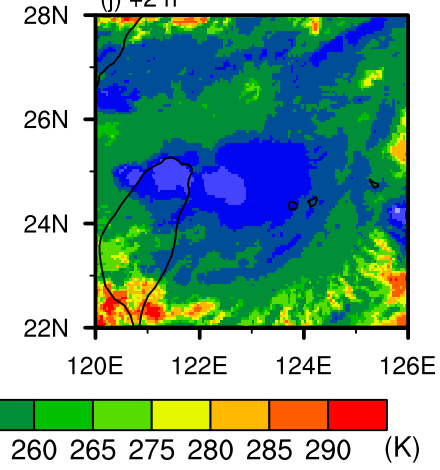

$190200210220235260265275280285290 \quad$ (K)

FIG. 3. Horizontal distribution of the Himawari-8 10.4- $\mu \mathrm{m}$ brightness temperature before and after the occurrence of a precipitating system in the (left) mature stage and (right) dissipating stage. The labels $(-4,-2$, and $+2 \mathrm{~h}$ ) indicate the time between the Himawari- 8 images and the precipitating system. The diagonal lines represent the edges of the DPR swaths. 

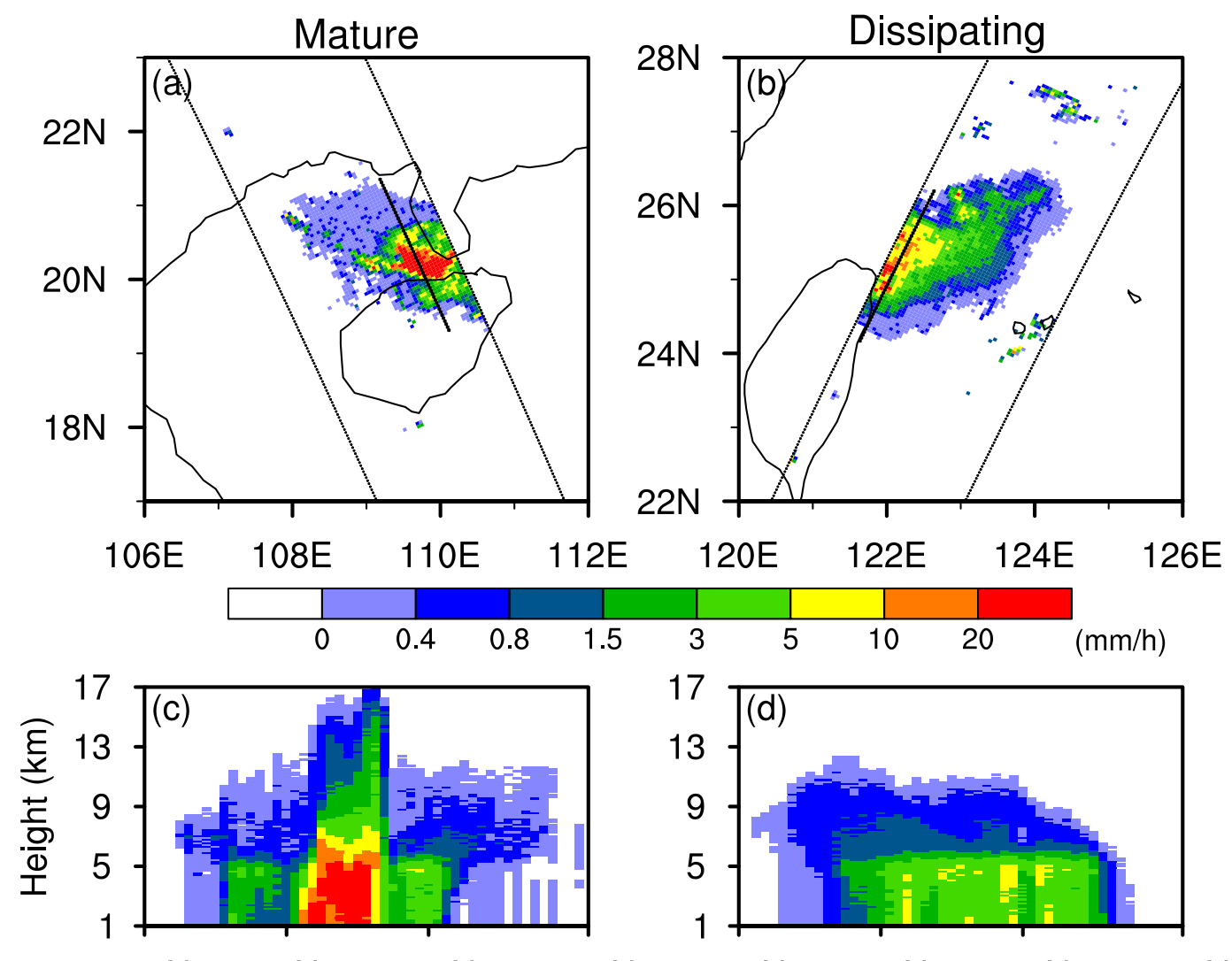

$\begin{array}{llllllllll}19.3 \mathrm{~N} & 20 \mathrm{~N} & 20.6 \mathrm{~N} & 21.4 \mathrm{~N} & 24.2 \mathrm{~N} & 24.8 \mathrm{~N} & 25.5 \mathrm{~N} & 26.2 \mathrm{~N}\end{array}$
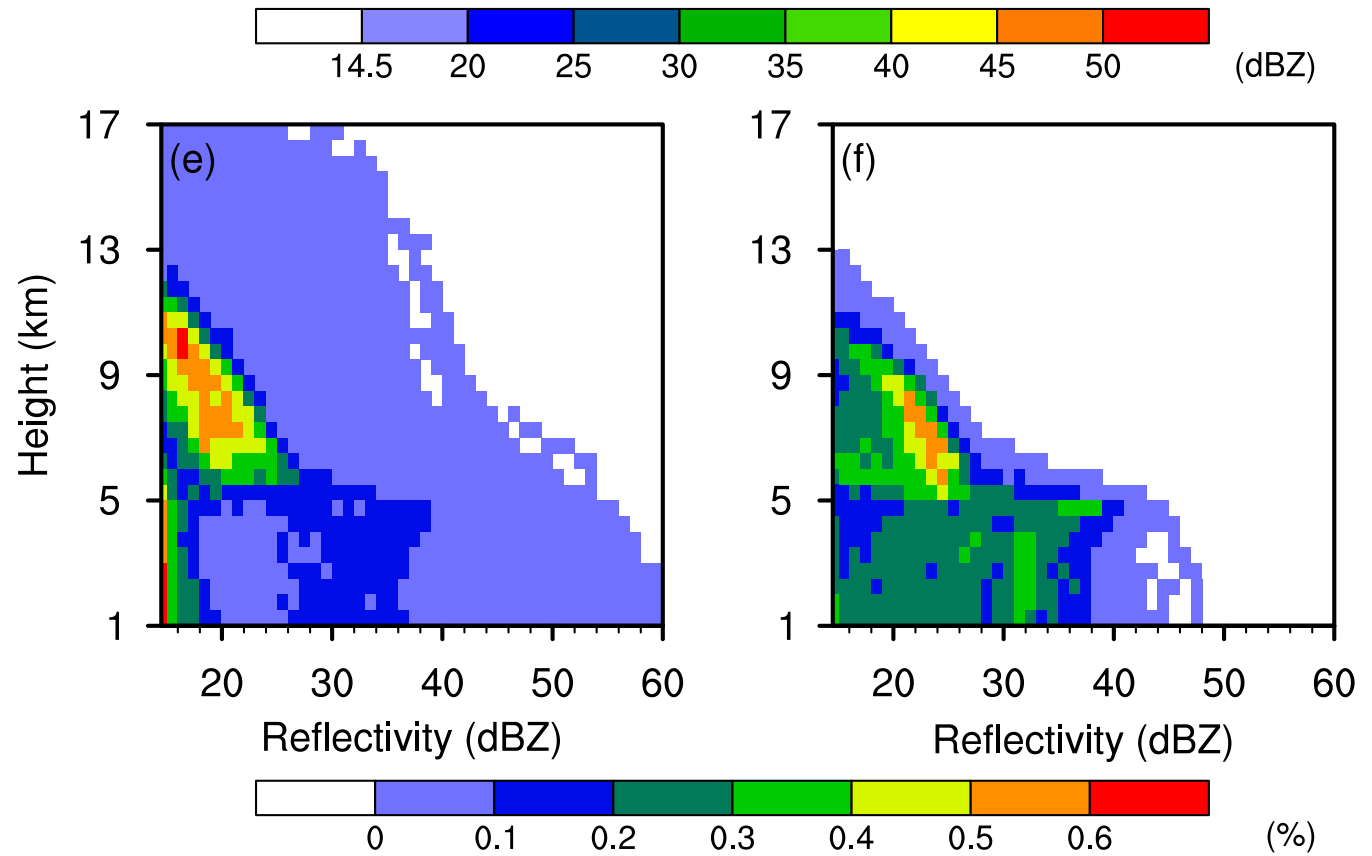

(\%)

FIG. 4. (a),(b) Horizontal distributions, (c),(d) vertical cross sections of the Ku-band attenuation corrected reflectivity, and (e),(f) contoured frequency by altitude diagram of the Ku-band reflectivity for precipitating systems in the (left) mature (occurring at 0220 UTC 2 Aug 2016) and (right) dissipating (occurring at 0510 UTC 14 Jun 2016) stages. Specifically, Figs. $3 \mathrm{e}$ and $3 \mathrm{f}$ were plotted from the entire precipitating system instead of the cross sections. 


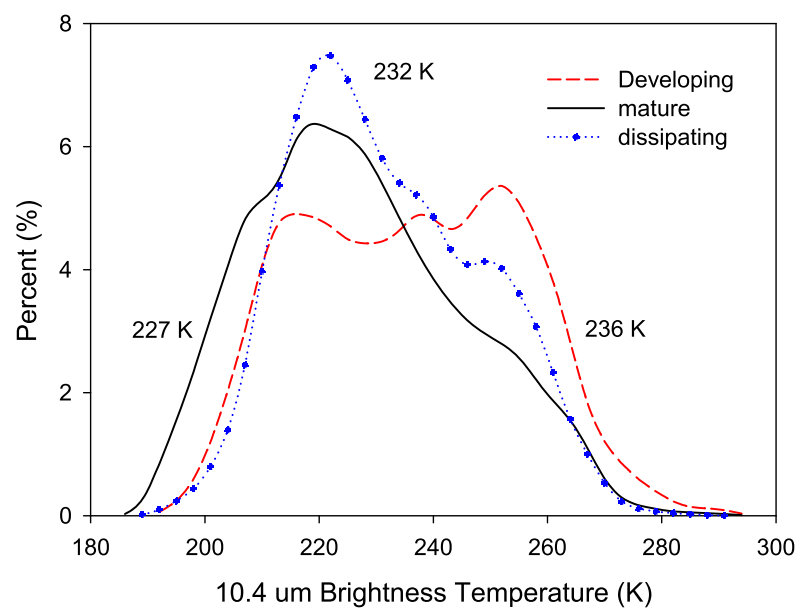

FIG. 5. PDF of the Himawari-8 $10.4-\mu \mathrm{m}$ brightness temperature for precipitation at different life stages of clouds derived from the 2ADPR product and Himawari-8 data for May-August 2016. The labels 227,232 , and $236 \mathrm{~K}$ are the mean brightness temperature of each line.

brightness temperature $<220 \mathrm{~K}$ in the mature stage, whereas this ratio was only $32 \%$ for the dissipating stage. We suggest that in the dissipating stage, the high clouds with the lowest brightness temperature collapsed much faster than the lower clouds. In the developing stage, the PDF of $\mathrm{TB}_{10.4}$ showed a unique trapezoidal structure at $220-260 \mathrm{~K}$, corresponding to a cloud-top height of 6-9 km (Lau and $\mathrm{Wu} 2011)$, indicating that precipitation mostly formed at this height.

PDF analyses of near-surface rain rates were also performed for each cloud stage. Figure 6a shows that the average rain rate was highest in the mature stage and lowest in the dissipating stage (also shown in Table 1). The total fraction of precipitation pixels with nearsurface rain rates $>10 \mathrm{~mm} \mathrm{~h}^{-1}$ were $6.66 \%, 8.41 \%$, and $4.99 \%$ for precipitating systems in the developing, mature, and dissipating stages, respectively. The PDFs of the near-surface rain rates for stratiform and convective precipitation are shown in Figs. $6 \mathrm{~b}$ and $6 \mathrm{c}$. The PDFs of stratiform precipitation were similar, and all peaked at $\sim 1 \mathrm{~mm} \mathrm{~h}^{-1}$ for every cloud stage, consistent with the TRMM statistical results reported by Yang and Nesbitt (2014). Except for the slightly stronger stratiform precipitation in the mature stage, the differences in stratiform precipitation between each stage were small (Fig. 6b). By contrast, the PDFs of convective precipitation in each stage were very different (Fig. 6c). Convective precipitation in the mature stage was accompanied by the largest near-surface rain rate, while convective precipitation was weakest in the developing stage. This suggests that the amount of water vapor was less in the developing stage, despite the largest proportion of convective precipitation. The PDFs of the rain rate for convective precipitation all showed bimodal peaks at 1 and $10 \mathrm{~mm} \mathrm{~h}^{-1}$, corresponding to shallow and deep convection, respectively. Convective precipitation in the mature stage showed smaller proportions of shallow convection than in the other stages.

\section{b. Vertical structures}

The CFAD analysis of precipitation radar reflectivity gives a good representation of the three-dimensional structural features of precipitation and has been used in numerous studies (Chen et al. 2017; Yuter and Houze 1995; Zhang et al. 2018). Figure 7 shows the CFADs of the DPR Ku-band reflectivity, which illustrate the impact of cloud stage and rain type. In general, the echo top of mature stage clouds is the highest (reaching $\sim 14 \mathrm{~km}$ ), followed by the echo top of developing stage clouds (reaching $\sim 13 \mathrm{~km}$ ), and the echo top of dissipating stage clouds is the lowest (reaching $\sim 12 \mathrm{~km}$ ) (Figs. 7a-c). The reflectivity of mature stage clouds is the strongest, and that of dissipating stage clouds is the weakest.

The CFADs of stratiform precipitation (Figs. 7d-f) show a clear bright-band feature at $5 \mathrm{~km}$, representing partially melted ice particles (Mason 1972). The echo top of stratiform precipitation was the highest in the mature stage, whereas the echo top in the developing stage was similar to that in the dissipating stage. The difference in stratiform reflectivity corresponding to the three life stages of clouds was also small, consistent with the near-surface rain rate for stratiform precipitation.

No obvious bright band was found in the CFADs of radar reflectivity for convective precipitation, and the echo top and intensity were both larger than those for stratiform precipitation (Figs. 7g-i). Comparing the CFADs of convective precipitation in each stage, it was found that convective precipitation in the mature stage was accompanied by the highest echo top and the strongest echo intensity. Convective precipitation in the developing stage showed more intense radar reflectivity than the dissipating stage above $8 \mathrm{~km}$, although the opposite was observed below $5 \mathrm{~km}$. This shows that convective precipitation in the developing stage had more large ice particles, but fewer large water particles. Consistent with Fig. 6, the near-surface radar reflectivity of convective precipitation showed bimodal peaks at 18 and $38 \mathrm{dBZ}$, corresponding to shallow and deep convection, respectively.

The vertical difference among the rainfall profiles in each stage is one of the main items of interest to the study. Figure 8 shows the average rainfall profiles of total, stratiform, and convective precipitation in each stage of the life cycle of clouds. The rain rate in the mature stage was the strongest for the total precipitation (Fig. 8a), whereas it was weakest in the dissipating stage. 

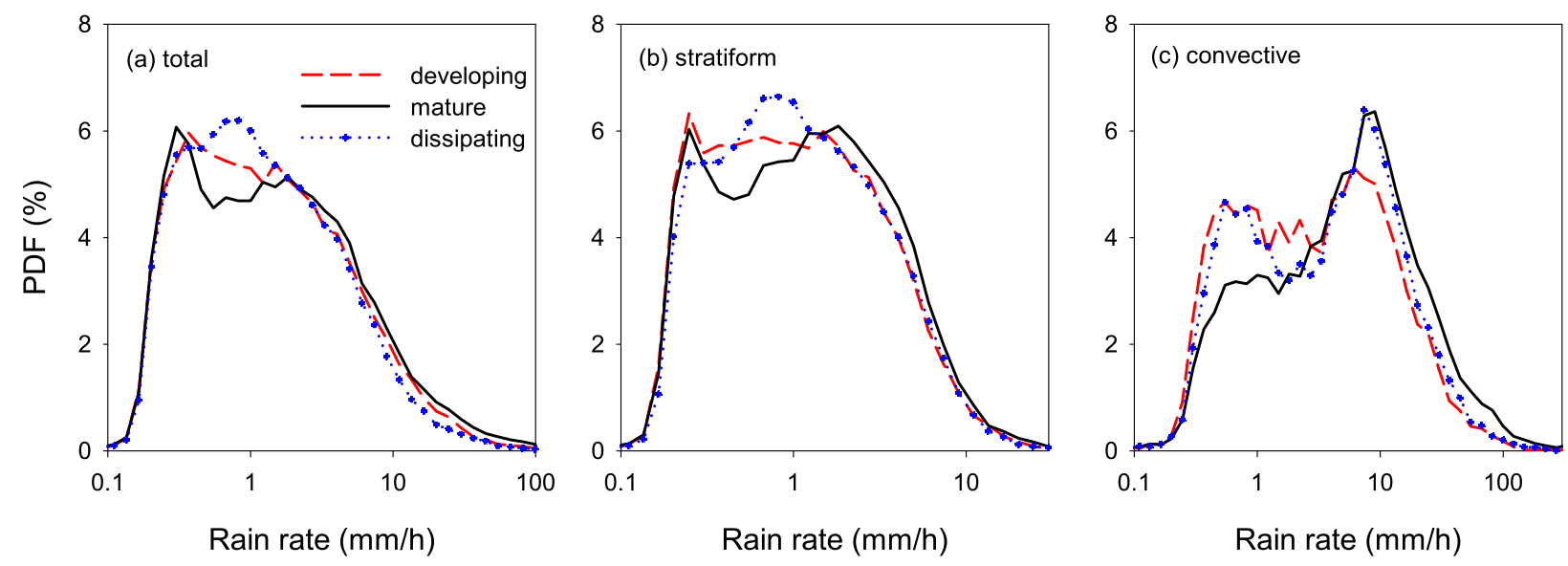

FIG. 6. PDF of near-surface rain rate for (a) total precipitation, (b) stratiform precipitation, and (c) convective precipitation in different life stages of clouds.

At a height of $8 \mathrm{~km}$, the average rain rates for the developing stage, mature stage, and dissipating stage were $1,1.11$, and $0.71 \mathrm{~mm} \mathrm{~h}^{-1}$, respectively, whereas they were $3.03,4.05$, and $2.89 \mathrm{~mm} \mathrm{~h}^{-1}$ at $1-\mathrm{km}$ height.

The rainfall intensity in the mature stage was strongest for stratiform and convective precipitation (Figs. 8b,c), but the intensity relationships between the developing and dissipating stages were fairly complex, especially for convective precipitation. At a height $\geq 6 \mathrm{~km}$, the rainfall intensity of convective precipitation in the developing stage was stronger than in the dissipating stage, indicating stronger convection and a greater precipitation of ice in the developing clouds. The opposite was observed at a height of $\leq 4 \mathrm{~km}$, indicating less liquid precipitation in the developing clouds. We therefore suggest that the strong upward flow in the developing stage brings large amounts of moisture from the lower layer to the upper layer. The differences between the average profiles of total precipitation and those of stratiform or convective precipitation should be linked with the different convective ratios in each stage.

\section{c. Microphysical features}

The DSD parameters provide an excellent opportunity to study the microphysical structure of precipitation (Hashimoto and Harimaya 2005; Ulbrich and Atlas 2007; Cao et al. 2008; Zhang et al. 2018). The DSD parameters from the GPM 2ADPR product include the effective droplet radius $D_{0}$ and the droplet concentration parameter $\left(\mathrm{dB} N_{0}\right)$. The $\mathrm{dB}$ stands for the mathematical operation of $10 \log _{10}()$.

To understand the microphysical processes in droplets for each life cycle stage of clouds, the average $D_{0}$ and $\mathrm{dB} N_{0}$ profiles are shown in Fig. 9. For the total precipitation, the $\mathrm{dBN} N_{0}$ was largest in the mature stage and smallest in the developing stage, indicating the different droplet concentrations in each cloud stage (Fig. 9a). Precipitation in the dissipating stage had the smallest $D_{0}$ value, indicating that the droplets were small, but relatively dense, in the dissipating stage (Fig. 9d). The droplets in the mature stage were largest below $4 \mathrm{~km}$, but smaller than in the developing stage above $4 \mathrm{~km}$, which can be linked with the frequent convective activities in developing clouds. Further analysis of the DSD parameters of stratiform and convective precipitation was carried out to determine the causes of the differences among the three cloud stages.

For stratiform precipitation (Figs. 9b,e), the DSD parameters were less affected by the life stage of the cloud. The order of $D_{0}$ or $\mathrm{dB} N_{0}$ depended on the total water content at each life stage, with the highest water content in the mature stage and the lowest water content in the developing stage.

By contrast, the DSD parameters of convective precipitation were significantly affected by the life stage of the cloud (Figs. 9c,f). In the developing stage, the droplet concentration was lowest in convective precipitation, but the effective radius of the droplets was large. In the dissipating stage, the droplet concentration was highest for convective precipitation, but the effective radius of the droplets was small. We suggest that the effective radius of droplets is linked to the strong upward motion observed in the developing stage of convective precipitation. The strong upward flow holds ice particles together, and the droplets grow by sublimation. In the mature stage, droplets fall to the ground accompanied by collision growth due to the presence of sufficient moisture in the clouds (Hocking 1959). As a result, convective precipitation in the mature stage consists of large, highdensity droplets, especially at lower levels. 

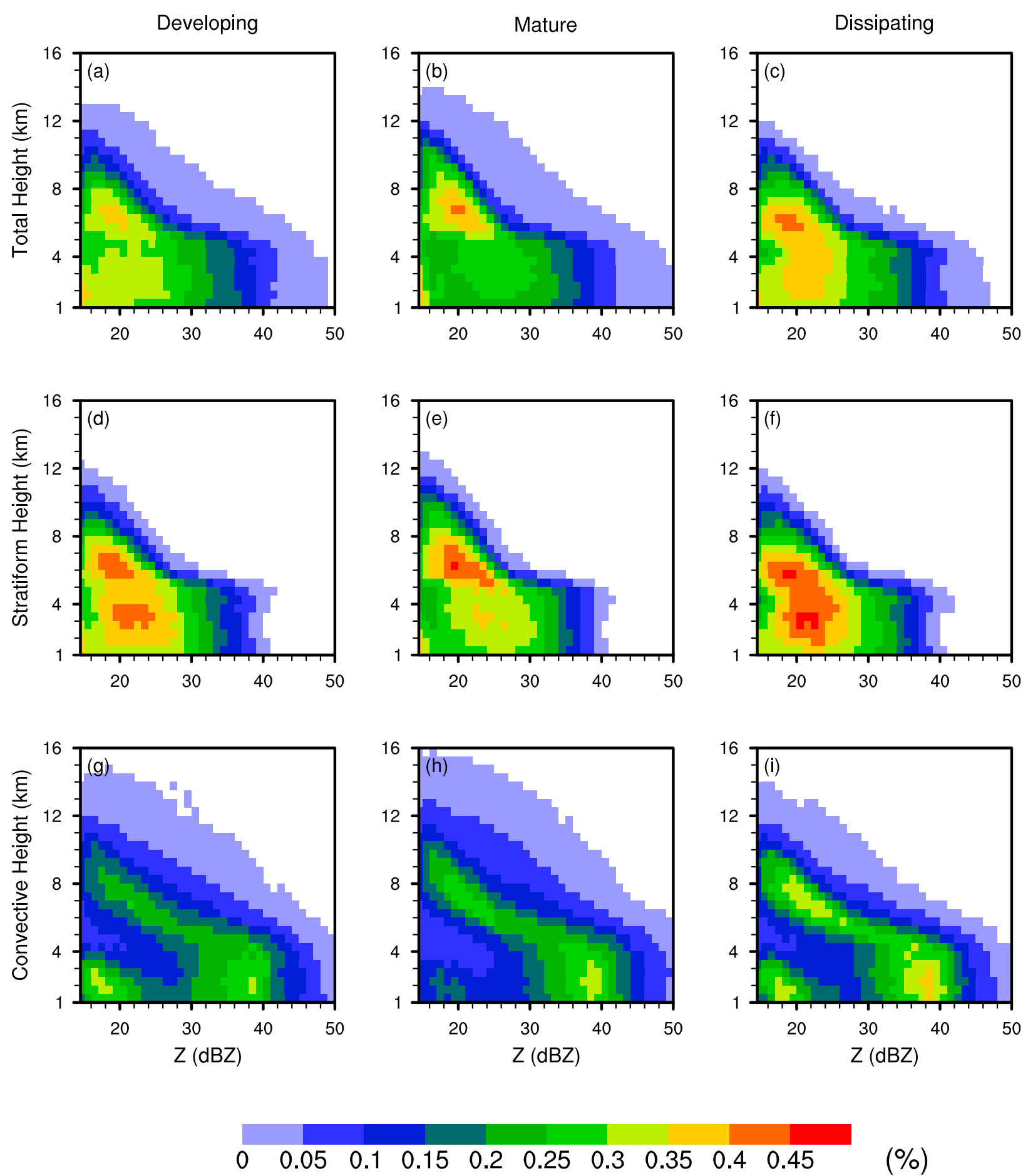

FIG. 7. Contoured frequency by altitude diagrams for the Ku-band reflectivity data for May-August 2016 for (a)-(c) total precipitation, (d)-(f) stratiform precipitation, and (g)-(i) convective precipitation in different life stages of clouds.

In addition, it is shown in Fig. 9 that the lines of $D_{0}$ above $8 \mathrm{~km}$ begin to increase for convective precipitations of developing stage, which might be linked with the strong upward air in the developing stage. In the case of strong upward air in the cloud, ice crystals must grow large enough in the ice layer before falling into the supercooled layer (Langmuir 1948).

Table 2 gives the standard deviations of the rain rates and DSD parameters and shows that the standard deviation was proportional to the value. 

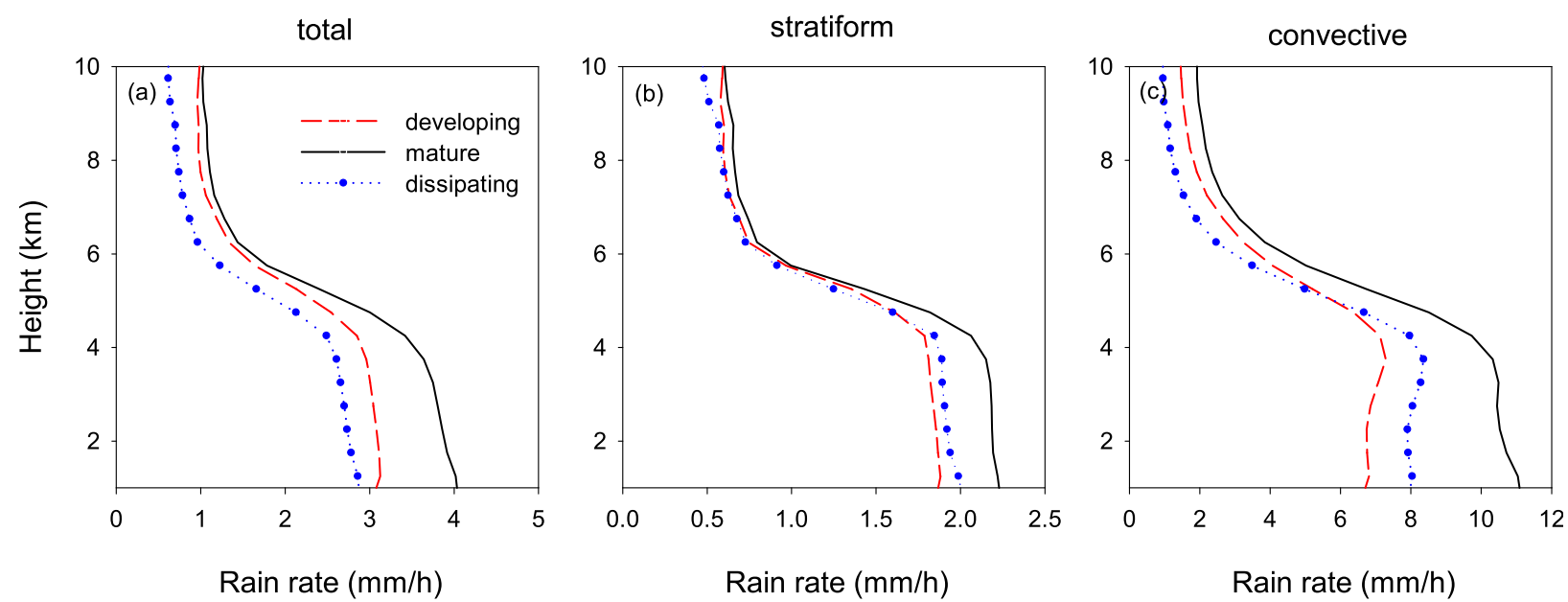

FIG. 8. Average rain-rate profiles for (a) total precipitation, (b) stratiform precipitation, and (c) convective precipitation in different life stages of clouds derived from the GPM 2ADPR product for May-August 2016.

The liquid water path (LWP) and ice water path (IWP) reflect the overall water vapor content of the atmosphere and are associated with micro-processes in clouds. The LWP and IWP change during the life cycle of clouds as a result of the accumulation of water vapor and the fall of hydrogels. As a result of the material changes between the ice and liquid layers, the ratio of the LWP to the IWP also changes constantly.

To quantify the differences in the LWP to IWP ratio in precipitation systems during the three different life stages, Fig. 10 shows the PDFs of the LWP and IWP. For total precipitation (Figs. 10a,d), the LWP and IWP were largest in the mature stage, showing the abundant water vapor present in mature stage clouds. The difference in the IWP was greater than the difference in the LWP, indicating that the difference in the moisture content was more significant above the freezing layer. There was no significant difference in the PDFs of the LWP (Fig. 10b) for stratiform precipitation, whereas the IWP of mature-stage clouds was larger than that of the developing or dissipating stages (Fig. 10e). This is related to the higher cloud-top height in the mature stage (Figs. 5, 6), which resulted in a thicker ice layer. For convective precipitation (Figs. 10c,f), the PDFs of the IWP showed a single peak, whereas the PDFs of the LWP showed double peaks, corresponding to shallow and deep convection, respectively. The LWP of convective precipitation in the developing stage was less than that in the dissipating stage, whereas it was the opposite for the IWP of convective precipitation. This confirms that there is more ice water, but less liquid water, in developing-stage clouds, which is linked to the strong upward airflow in these clouds.
Numerous studies have focused on the relationship between the top height of storms and the infrared brightness temperature (Masunaga et al. 2005). Specifically, two features were seen in the two-dimensional histogram of the PR echo-top height and the Visible and Infrared Scanner (VIRS) brightness temperature: a peak in shallow convection with echo-top heights of $2 \mathrm{~km}$ and a vertical ridge at $5 \mathrm{~km}$ in the $\mathrm{PR}$ echo-top height (Masunaga et al. 2005). We studied the relationships between the DPR storm-top height and the Himawari-8 $10.4-\mu \mathrm{m}$ brightness temperature based on our classification method.

Figures 11a-c show the two-dimensional PDF in echo-top height and brightness temperature for the total precipitation in each stage of the cloud life cycle. When the storm-top height was $>5.5 \mathrm{~km}$, the height of the freezing layer, the storm-top height decreased as the brightness temperature increased. However, because the $\mathrm{Ku}$ band is extremely sensitive to partially melted ice particles (Mason 1972), the storm-top height did not decrease with the increase in brightness temperature when the storm-top height was $<5.5 \mathrm{~km}$. There is only one noticeable feature in the two-dimensional PDFs: the brightness temperature corresponding to this feature was largest in the developing stage, whereas the storm-top height corresponding to the feature was lowest in the dissipating stage, consistent with the statistics (Figs. 5, 7).

The characteristics for the two-dimensional PDF of stratiform precipitation (Figs. 11d-f) were basically the same as those for the total precipitation, but with a more concentrated distribution. Two noticeable features were found in the two-dimensional PDFs for convective 

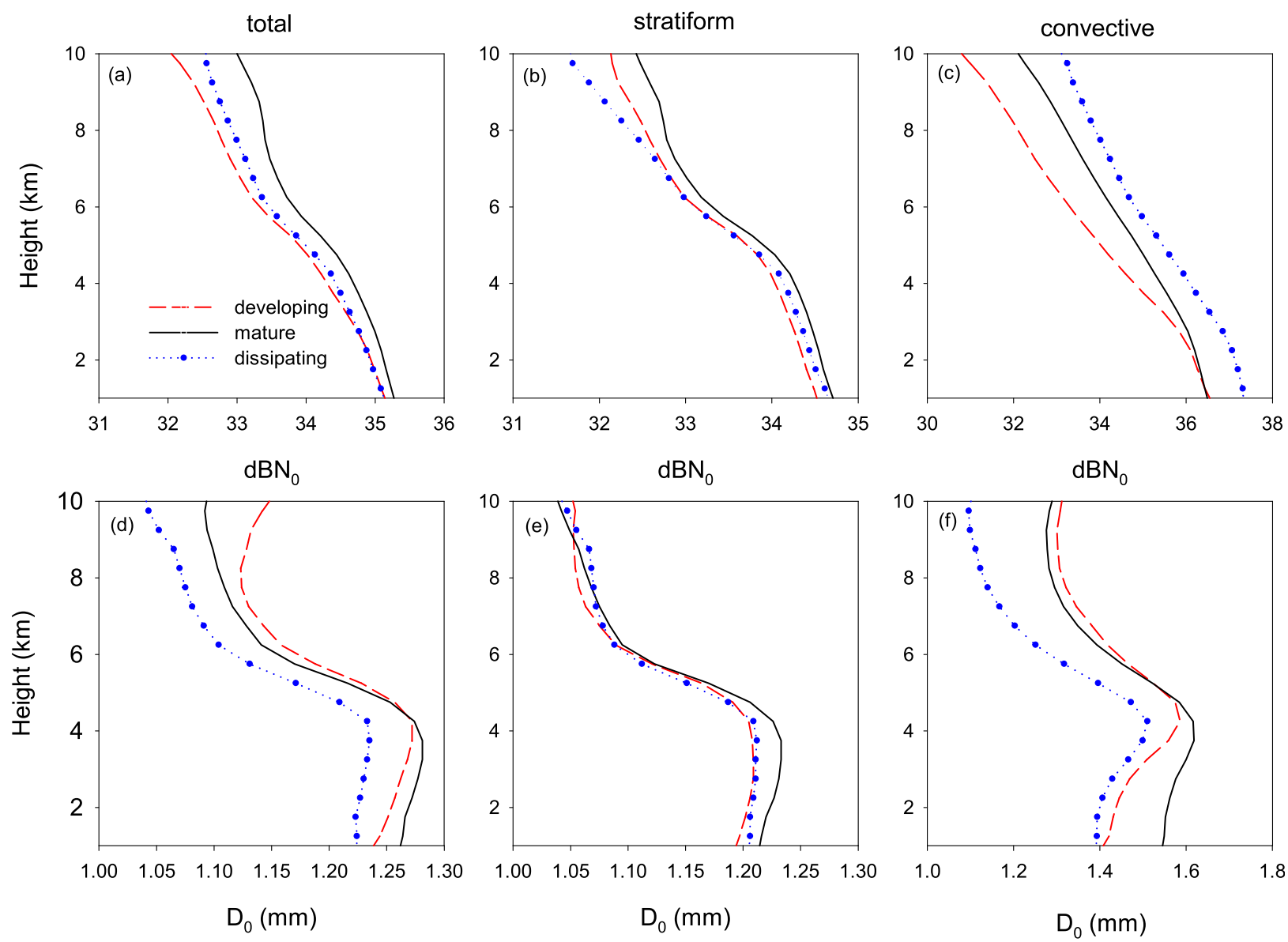

FIG. 9. Average values of the (a)-(c) droplet concentration and (d)-(f) droplet effective radius in different life stages of clouds derived from the GPM 2ADPR product for May-August 2016.

precipitation (Figs. 11g-i), showing a shallow convection feature at a storm-top height of $2-4 \mathrm{~km}$ and a vertical bridge similar to that seen for the total precipitation. Compared with the results from the Pacific Ocean reported by Masunaga et al. (2005), the storm-top height of the shallow convection was higher in east
China. A comparison of the two-dimensional PDFs of convective precipitation in each stage showed that the developing stage was accompanied by the largest proportion of shallow convection, followed by the dissipating stage. The mature stage had the smallest proportion of shallow convection.

TABLE 2. Standard deviations of rain rate $\left(\mathrm{dB} N_{0}\right)$ and droplet effective radius $\left(D_{0}\right)$ at heights of $10,5.5$, and $1 \mathrm{~km}$ for precipitations in each stage of the cloud life cycle.

\begin{tabular}{lcccc}
\hline \hline & Height $(\mathrm{km})$ & Developing stage & Mature stage & Dissipating stage \\
\hline Standard deviation of rain rate $\left(\mathrm{mm} \mathrm{h}^{-1}\right)$ & 10 & 1.713 & 2.223 & 0.602 \\
& 5.5 & 3.302 & 10.837 & 3.015 \\
Standard deviation of dB $N_{0}$ & 1 & 7.013 & 4.182 & 3.791 \\
& 10 & 4.401 & 3.983 & 3.792 \\
Standard deviation of $D_{0}(\mathrm{~mm})$ & 5.5 & 4.312 & 0.193 & 3.362 \\
& 1 & 0.35 & 0.325 & 0.187 \\
\end{tabular}



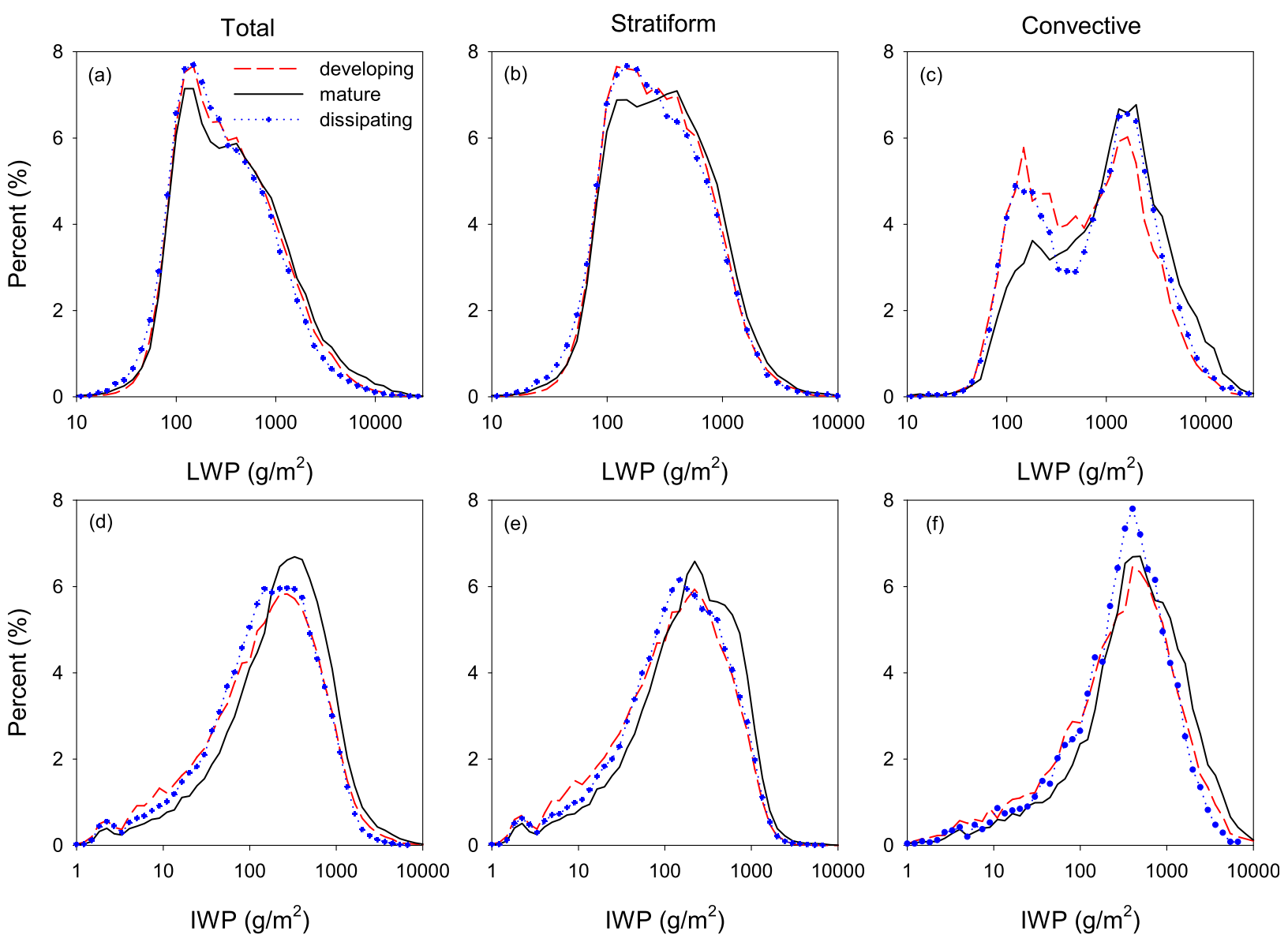

FIG. 10. PDF of the (a)-(c) LWP and (d)-(f) IWP for precipitation in different life stages of clouds.

\section{Discussion and conclusions}

In an attempt to understand the effects of the life cycle of clouds on the vertical structure of precipitation in east China, precipitating systems were identified using precipitation data from the GPM DPR from May to August 2016. The precipitating systems were classified into three cloud life stages (developing, mature, and dissipating) based on the Himawari-8 $10.4-\mu \mathrm{m}$ brightness temperature before and after the precipitation event. Using both case studies and statistical studies, we focused on the structural characteristics of precipitation in each life cycle stage, including the radar reflectivity, rain-rate profile, and DSD parameters, and analyzed their microphysical properties. Figure 12 is a schematic diagram of the properties of precipitation in each life cycle stage.

We first focused on the overall characteristics of precipitating systems at different stages, including the scale, convective ratio, rain-top height, and brightness temperature. In the developing stage of the cloud, convective activities were strong, but there was less water vapor. The precipitating systems at this stage had the highest convective ratio and high rain tops, but only small areas of precipitation. The corresponding infrared brightness temperature of the precipitating pixels identified by DPR mostly appeared in the interval $220-260 \mathrm{~K}$. As the cloud entered the mature stage, the convective ratio in the precipitating systems decreased, and the rain top reached its peak height. The area of precipitation in the mature stage was larger than that in the developing stage, and the infrared brightness temperature was the lowest of all three stages. The cloud continued to spread horizontally after the mature stage. However, due to the lack of upward flow in the cloud, the upper cloud layer collapsed, and the cloud water content decreased, indicating that the cloud had entered the dissipating stage. Precipitating systems occurring in the dissipating stage covered the largest area, but had the lowest rain top and lowest convective ratio.

Based on the type of rain, the reflectivity profiles, and the rain-rate profiles provided by the DPR instrument, we studied the vertical structures of precipitating 

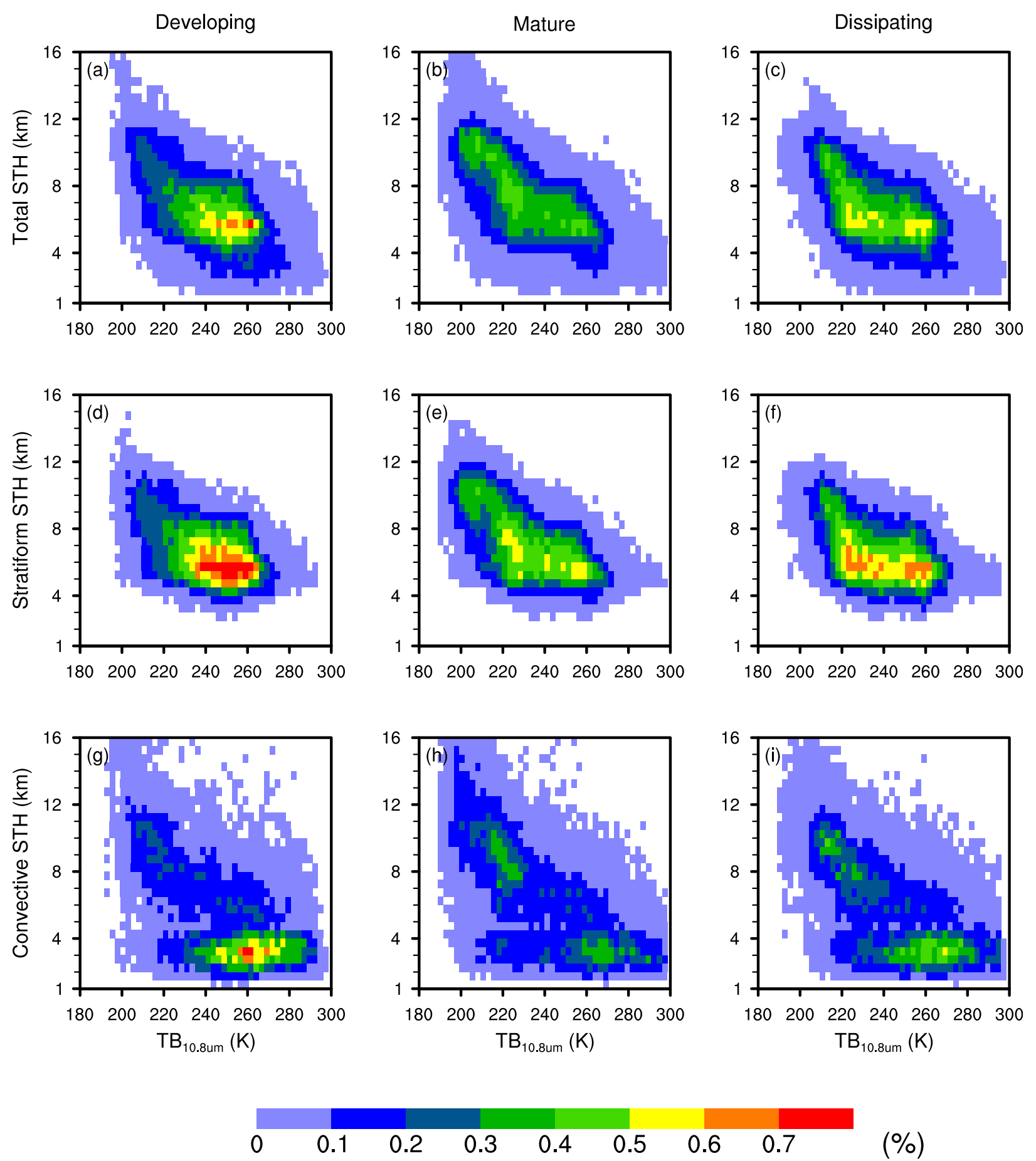

(\%)

FIG. 11. Two-dimensional PDF in echo-top height (STH) and $10.8-\mu \mathrm{m}$ brightness temperature $\left(\mathrm{TB}_{10.8 \mu \mathrm{m}}\right)$ for (a)-(c) total precipitation, (d)-(f) stratiform precipitation, and (g)-(i) convective precipitation in different life stages of clouds.

systems in each stage in more detail. The precipitation intensity for the total precipitation was highest at the mature stage, followed by the developing stage, and then the dissipating stage. This sequence of precipitation intensity followed the sequence for the cloud water content in each stage. However, for convective precipitation, further analysis showed that convective precipitation in the developing system was more intense than that in the dissipating stage below $5 \mathrm{~km}$, but the opposite was observed above $5 \mathrm{~km}$. This reflects the 


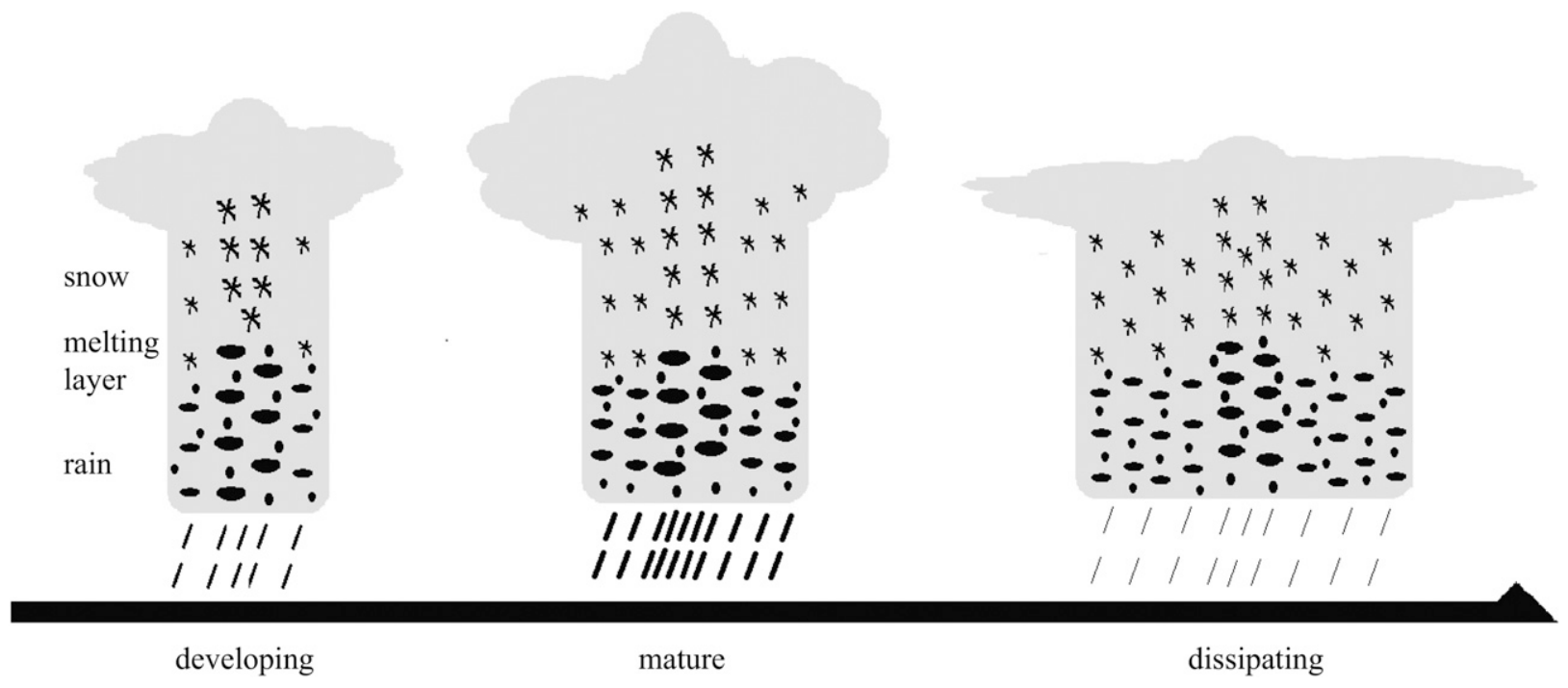

FIG. 12. Schematic diagram of precipitating systems in different life stages of clouds.

impact of strong convection in developing clouds. The CFAD analysis of the radar reflectivity of convective precipitation showed large proportions of shallow convection in the developing and dissipating stages, but smaller proportions in the mature stage.

As a result of the joint detection of dual-frequency radar, the GPM center provides particle spectrum information through dual-frequency algorithms. Based on the DSD profiles from 2ADPR, we investigated the microphysical structures of precipitation systems at each life cycle stage. In the developing stage, the strong upward motion forced by frequent convective activity can hold small particles and prevent them from dropping. Hence, the effective radius of precipitation in the developing stage was large, especially for ice particles above $5.5 \mathrm{~km}$, whereas the droplet density was the lowest of all three stages. The LWP and IWP were abundant in the mature stage, so the precipitating systems in this stage were accompanied by the highest droplet concentration and the largest radius. The upward flow was weakest in the dissipating stage, making it easy for small particles to fall. Hence, the droplets of the precipitating systems in the dissipating stage were the smallest, although the droplet concentration was higher than in the developing stage.

Some of the uncertainties and limitations of the study include the following. Because the brightness temperature of large-scale stratiform systems does not change much before and after precipitation, large-scale stratiform precipitating systems were removed from our algorithm of cloud life stages. Therefore, the actual proportion of stratiform precipitation should be slightly higher than that in our results. In addition, due to the limitations of data acquisition, only precipitating systems in China from May to August 2016 were studied. The concentrated research period and small sample size may limit our results. Future studies using joint observations of precipitation radar and geostationary satellites over a longer time period will reduce the uncertainty in the results, and an optimized stage identification algorithm for large-scale stratiform systems will help us to more comprehensively understand the relationship between precipitation stage and the characteristics of precipitation.

Acknowledgments. This work is supported by the National Natural Science Foundation of China (NSFC Grants 41675041, 41620104009, and 41230419) and the Fundamental Research Funds for the Central Universities (Grant WK6030000068). Thanks also are extended to the Japan Aerospace Exploration Agency (JAXA), the National Institute of Communication Technology (NICT), and the Japan Meteorological Agency for providing GPM DPR and Himawari-8 datasets.

\section{REFERENCES}

Arnaud, Y., M. Desbois, and J. Maizi, 1992: Automatic tracking and characterization of African convective systems on Meteosat pictures. J. Appl. Meteor., 31, 443-453, https://doi.org/ 10.1175/1520-0450(1992)031<0443:ATACOA > 2.0.CO;2.

Barros, A. P., M. Joshi, J. Putkonen, and D. W. Burbank, 2000: A study of the 1999 monsoon rainfall in a mountainous region in central Nepal using TRMM products and rain gauge observations. Geophys. Res. Lett., 27, 3683-3686, https://doi.org/ 10.1029/2000GL011827.

Berg, W., C. Kummerow, and C. A. Morales, 2002: Differences between East and West Pacific rainfall systems. J. Climate, 15, 3659-3672, https://doi.org/10.1175/1520-0442(2002)015<3659: DBEAWP $>2.0 . \mathrm{CO} ; 2$ 
Bessho, K., and Coauthors, 2016: An introduction to Himawari-8/ 9-Japan's new-generation geostationary meteorological satellites. J. Meteor. Soc. Japan, 94, 151-183, https://doi.org/ 10.2151/jmsj.2016-009.

Byers, H. R., and R. R. Braham, 1949: The Thunderstorm: Report of the Thunderstorm Project. U.S. Government Printing Office, $287 \mathrm{pp}$.

Cao, Q., G. Zhang, E. Brandes, T. Schuur, A. Ryzhkov, and K. Ikeda, 2008: Analysis of video disdrometer and polarimetric radar data to characterize rain microphysics in Oklahoma. J. Appl. Meteor. Climatol., 47, 2238-2255, https:// doi.org/10.1175/2008JAMC1732.1.

Carbone, R. E., and L. D. Nelson, 1978: The evolution of raindrop spectra in warm-based convective storms as observed and numerically modeled. J. Atmos. Sci., 35, 2302-2314, https://doi.org/ 10.1175/1520-0469(1978)035<2302:TEORSI >2.0.CO;2.

Chen, F. J., Y. F. Fu, P. Liu, and Y. J. Yang, 2016: Seasonal variability of storm top altitudes in the tropics and subtropics observed by TRMM PR. Atmos. Res., 169, 113-126, https:// doi.org/10.1016/j.atmosres.2015.09.017.

Chen, Y. L., 1988: Life cycle effects of cloud clusters on the moisture distribution over the eastern Atlantic. J. Meteor. Soc. Japan, 66, 387-391, https://doi.org/10.2151/jmsj1965.66.2_387.

Chen, Y. L., Y. F. Fu, T. Xian, and X. Pan, 2017: Characteristics of cloud cluster over the steep southern slopes of the Himalayas observed by CloudSat. Int. J. Climatol., 37, 4043-4052, https:// doi.org/10.1002/joc.4992.

Cho, H. R., 1977: Contributions of cumulus cloud life-cycle effects to the large-scale heat and moisture budget equations. J. Atmos. Sci., 34, 87-97, https://doi.org/10.1175/1520-0469 (1977)034<0087:COCCLC $>2.0 . C O ; 2$.

Da, C., 2015: Preliminary assessment of the Advanced Himawari Imager (AHI) measurement onboard Himawari-8 geostationary satellite. Remote Sens. Lett., 6, 637-646, https://doi.org/ 10.1080/2150704X.2015.1066522.

Fiolleau, T., and R. Roca, 2013a: An algorithm for the detection and tracking of tropical mesoscale convective systems using infrared images from geostationary satellite. IEEE Trans. Geosci. Remote Sens., 51, 4302-4315, https://doi.org/10.1109/ TGRS.2012.2227762.

$\longrightarrow$, and — 2013b: Composite life cycle of tropical mesoscale convective systems from geostationary and low Earth orbit satellite observations: Method and sampling considerations. Quart. J. Roy. Meteor. Soc., 139, 941-953, https://doi.org/10.1002/qj.2174.

Fisher, B. L., 2004: Climatological validation of TRMM TMI and PR monthly rain products over Oklahoma. J. Appl. Meteor., 43, 519-535, https://doi.org/10.1175/1520-0450 (2004)043<0519:CVOTTA > 2.0.CO;2.

Fu, Y. F., and G. S. Liu, 2001: The variability of tropical precipitation profiles and its impact on microwave brightness temperatures as inferred from TRMM data. J. Appl. Meteor., 40, 2130-2143, https://doi.org/10.1175/1520-0450 (2001) $040<2130$ :TVOTPP $>2.0$. CO;2.

—, Y. H. Lin, G. S. Liu, and Q. Wang, 2003: Seasonal characteristics of precipitation in 1998 over East Asia as derived from TRMM PR. Adv. Atmos. Sci., 20, 511-529, https://doi.org/ 10.1007/BF02915495.

, G. S. Liu, G. X. Wu, R. C. Yu, Y. P. Xu, Y. Wang, R. Li, and Q. Liu, 2006: Tower mast of precipitation over the central Tibetan Plateau summer. Geophys. Res. Lett., 33, L05802, https://doi.org/10.1029/2005GL024713.

Hamada, A., and Y. N. Takayabu, 2016: Improvements in detection of light precipitation with the Global Precipitation Measurement dual-frequency precipitation radar (GPM DPR). J. Atmos. Oceanic Technol., 33, 653-667, https://doi.org/10.1175/JTECH-D-15-0097.1.

Hashimoto, A., and T. Harimaya, 2005: Characteristics of raindrop size distribution dependent on the life stage of a convective precipitation cloud in the Baiu season. J. Meteor. Soc. Japan, 83, 641-649, https://doi.org/10.2151/jmsj.83.641.

Hobbs, P. V., 1989: Research on clouds and precipitation: Past, present, and future. Part I. Bull. Amer. Meteor. Soc., 70, 282285, https://doi.org/10.1175/1520-0477-70.3.282.

Hocking, L. M., 1959: The collision efficiency of small drops. Quart. J. Roy. Meteor. Soc., 85, 44-50, https://doi.org/ 10.1002/qj.49708536305.

Hou, A. Y., and Coauthors, 2014: The Global Precipitation Measurement Mission. Bull. Amer. Meteor. Soc., 95, 701-722, https://doi.org/10.1175/BAMS-D-13-00164.1.

Houze, R. A., 1981: Structures of atmospheric precipitation systems: A global survey. Radio Sci., 16, 671-689, https://doi.org/ 10.1029/RS016i005p00671.

_- D. C. Wilton, and B. F. Smull, 2007: Monsoon convection in the Himalayan region as seen by the TRMM Precipitation Radar. Quart. J. Roy. Meteor. Soc., 133, 1389-1411, https:// doi.org/10.1002/qj.106.

Iguchi, T., and Coauthors, 2012: An overview of the precipitation retrieval algorithm for the dual-frequency precipitation radar (DPR) on the global precipitation measurement (GPM) mission's core satellite. Earth Observing Missions and Sensors: Development, Implementation, and Characterization II, H. Shimoda et al., Eds., International Society for Optics and Photonics (SPIE Proceedings, Vol. 8528), 85281C, https:// doi.org/10.1117/12.977352.

Inoue, T., and K. Aonashi, 2000: A comparison of cloud and rainfall information from instantaneous visible and infrared scanner and precipitation radar observations over a frontal zone in East Asia during June 1998. J. Appl. Meteor., 39, 2292-2301, https://doi.org/10.1175/1520-0450(2001)040<2292: ACOCAR $>2.0 . C O ; 2$.

—, D. Vila, K. Rajendran, A. Hamada, X. Wu, and L. A. T. Machado, 2009: Life cycle of deep convective systems over the eastern tropical Pacific observed by TRMM and GOES-W. J. Meteor. Soc. Japan, 87A, 381-391, https://doi.org/10.2151/ jmsj.87A.381.

Kojima, M., and Coauthors, 2012: Dual-frequency precipitation radar (DPR) development on the global precipitation measurement (GPM) core observatory. Earth Observing Missions and Sensors: Development, Implementation, and Characterization II, H. Shimoda et al., Eds., International Society for Optics and Photonics (SPIE Proceedings, Vol. 8528), 85281A, https://doi.org/10.1117/12.976823.

Kondo, Y., A. Higuchi, and K. Nakamura, 2006: Small-scale cloud activity over the Maritime Continent and the western Pacific as revealed by satellite data. Mon. Wea. Rev., 134, 1581-1599, https://doi.org/10.1175/MWR3132.1.

Kotsuki, S., K. Terasaki, and T. Miyoshi, 2014: GPM/DPR precipitation compared with a $3.5-\mathrm{km}$-resolution NICAM simulation. SOLA, 10, 204-209, https://doi.org/10.2151/ sola.2014-043.

Langmuir, I., 1948: The production of rain by a chain reaction in cumulus clouds at temperatures above freezing. J. Meteor., 5, 175-192, https://doi.org/10.1175/1520-0469(1948)005<0175: TPORBA $>2.0 . \mathrm{CO} ; 2$.

Lau, K.-M., and H.-T. Wu, 2011: Climatology and changes in tropical oceanic rainfall characteristics inferred from Tropical Rainfall Measuring Mission (TRMM) data (1998-2009). 
J. Geophys. Res., 116, D17111, https://doi.org/10.1029/ 2011JD015827.

L'Ecuyer, T., and G. Stephens, 2002: An estimation-based precipitation retrieval algorithm for attenuating radars. J. Appl. Meteor., 41, 272-285, https://doi.org/10.1175/1520-0450(2002) $041<0272$ :AEBPRA $>2.0 . \mathrm{CO} ; 2$.

Li, W., and C. Schumacher, 2011: Thick anvils as viewed by the TRMM Precipitation Radar. J. Climate, 24, 1718-1735, https:// doi.org/10.1175/2010JCLI3793.1.

Liu, C. T., and E. J. Zipser, 2005: Global distribution of convection penetrating the tropical tropopause. J. Geophys. Res., 110 D23104, https://doi.org/10.1029/2005JD006063.

— , and — , 2015: The global distribution of largest, deepest, and most intense precipitation systems. Geophys. Res. Lett. 42, 3591-3595, https://doi.org/10.1002/2015GL063776.

Liu, P., C. Y. Li, Y. Wang, and Y. F. Fu, 2013: Climatic characteristics of convective and stratiform precipitation over the tropical and subtropical areas as derived from TRMM PR. Sci. China Earth Sci., 56, 375-385, https://doi.org/10.1007/s11430-012-4474-4.

Machado, L., W. B. Rossow, R. L. Guedes, and A. W. Walker, 1998: Life cycle variations of mesoscale convective systems over the Americas. Mon. Wea. Rev., 126, 1630-1654, https://doi.org/ 10.1175/1520-0493(1998)126<1630:LCVOMC > 2.0.CO;2.

Mapes, B. E., and R. A. Houze, 1993: Cloud clusters and superclusters over the oceanic warm pool. Mon. Wea. Rev., 121, 1398-1416, https://doi.org/10.1175/1520-0493(1993)121<1398: CCASOT $>2.0 . \mathrm{CO} ; 2$.

Mason, B. J., 1972: The physics of the thunderstorm. Proc. Roy. Soc. London, 327A, 433, https://doi.org/10.1098/ rspa.1972.0056

Masunaga, H., T. S. L'Ecuyer, and C. D. Kummerow, 2005: Variability in the characteristics of precipitation systems in the tropical Pacific. Part I: Spatial structure. J. Climate, 18, 823840, https://doi.org/10.1175/JCLI-3304.1.

Mathon, V., and H. Laurent, 2001: Life cycle of Sahelian mesoscale convective cloud systems. Quart. J. Roy. Meteor. Soc., 127, 377-406, https://doi.org/10.1002/qj.49712757208.

Nesbitt, S. W., E. J. Zipser, and D. J. Cecil, 2000: A census of precipitation features in the tropics using TRMM: Radar, ice scattering, and lightning observations. J. Climate, 13, 4087-4106, https:// doi.org/10.1175/1520-0442(2000)013<4087:ACOPFI>2.0.CO;2.

Rose, C. R., and V. Chandrasekar, 2006: A GPM dual-frequency retrieval algorithm: DSD profile-optimization method J. Atmos. Oceanic Technol., 23, 1372-1383, https://doi.org/ 10.1175/JTECH1921.1.

Schumacher, C., and R. A. Houze, 2003: Stratiform rain in the tropics as seen by the TRMM precipitation radar.
J. Climate, 16, 1739-1756, https://doi.org/10.1175/1520-0442 (2003)016<1739:SRITTA > 2.0.CO;2.

Simpson, J., R. F. Adler, and G. R. North, 1988: A proposed Tropical Rainfall Measuring Mission (TRMM) satellite. Bull. Amer. Meteor. Soc., 69, 278-295, https://doi.org/10.1175/15200477(1988)069<0278:APTRMM>2.0.CO;2.

Takahashi, T., 1975: Electric charge life cycle in warm clouds. J. Atmos. Sci., 32, 123-142, https://doi.org/10.1175/1520-0469 (1975)032<0123:ECLCIW>2.0.CO;2.

Ulbrich, C. W., and D. Atlas, 2007: Microphysics of raindrop size spectra: Tropical continental and maritime storms. J. Appl. Meteor. Climatol., 46, 1777-1791, https://doi.org/10.1175/ 2007JAMC1649.1.

Williams, M., and R. A. Houze, 1987: Satellite-observed characteristics of winter monsoon cloud clusters. Mon. Wea. Rev., 115, 505-519, https://doi.org/10.1175/1520-0493(1987) $115<0505:$ SOCOWM $>2.0 . \mathrm{CO} ; 2$.

Witte, M. K., P. Y. Chuang, and G. Feingold, 2014: On clocks and clouds. Atmos. Chem. Phys., 14, 6729-6738, https://doi.org/ 10.5194/acp-14-6729-2014.

Xian, T., and Y. F. Fu, 2015: Characteristics of tropopausepenetrating convection determined by TRMM and COSMIC GPS radio occultation measurements. J. Geophys. Res. Atmos., 120, 7006-7024, https://doi.org/10.1002/2014JD022633.

Yang, S., and S. W. Nesbitt, 2014: Statistical properties of precipitation as observed by the TRMM precipitation radar. Geophys. Res. Lett., 41, 5636-5643, https://doi.org/10.1002/ 2014GL060683.

Yuter, S. E., and R. A. Houze, 1995: Three-dimensional kinematic and microphysical evolution of Florida cumulonimbus. Part II: Frequency distributions of vertical velocity, reflectivity, and differential reflectivity. Mon. Wea. Rev., 123, 1941-1963, https://doi.org/10.1175/1520-0493 (1995) $123<1941$ :TDKAME > 2.0.CO;2.

Zhang, A. Q., Y. F. Fu, Y. L. Chen, G. S. Liu, and X. D. Zhang, 2018: Impact of the surface wind flow on precipitation characteristics over the southern Himalayas: GPM observations. Atmos. Res., 202, 10-22, https://doi.org/10.1016/ j.atmosres.2017.11.001.

Zhao, M., and P. H. Austin, 2005: Life cycle of numerically simulated shallow cumulus clouds. Part I: Transport. J. Atmos. Sci., 62, 1269-1290, https://doi.org/10.1175/JAS3414.1.

Zipser, E. J., and K. R. Lutz, 1994: The vertical profile of radar reflectivity of convective cells: A strong indicator of storm intensity and lightning probability? Mon. Wea. Rev., 122, 1751-1759, https://doi.org/10.1175/1520-0493(1994)122<1751: TVPORR $>2.0 . \mathrm{CO} ; 2$. 